\title{
COMPARATIVE ANALYSIS OF MULTIPLE FUSION APPROACHES FOR MULTIMODAL BIOMETRIC SYSTEMS
}

Shiraz Anwar ${ }^{1}$, Surinder ${ }^{2}$

Abstract: This paper presents comparative analysis of different fusion approaches which are widely used in multimodal biometric systems. Fusion of multiple biometric traits i.e. multimodal biometric system and information fusion at the match score level are the most commonly used approaches in multibiometric systems. Fusion at sensor level suffer from sensor interoperability problem, fusion at feature level suffer from feature set incompatibility problem, and fusion at decision level contains least amount of information i.e. the decisions output by the individual biometric matchers to be fused. Among the type of biometric information fused i.e. multi-sensor, multi-algorithm, multi-instance, multi-sample, and multimodal, the fifth multibiometric system i.e. multimodal seems better choice because it is more robust to noise, addresses the problem of nonuniversality, involves more than one biometric trait, improves the matching accuracy, and provides protection against spoof attacks. Fusion methodologies depend upon the type of biometric information fused and level of fusion.

Keywords: Biometric, Fusion, Sensors, Match Score, FAR, FRR, FMR, ROC, EER

\section{INTRODUCTION}

Information fusion in biometrics presents an elegant way to enhance the matching accuracy of a biometric system. Determining the sources of biometric information that would result in the best matching performance is not an easy task. Multibiometric systems that have been proposed in the literature can be categorized based on three parameters, i.e., (i) type of biometric information fused, (ii) level of fusion, and (iii) fusion methodology. In general, the choice of these three parameters depends on the application scenario and it has been found that they have a profound influence on the performance of a multibiometric system [10-16].

\section{LITERATURE SURVEY}

A multisensory multimodal biometric system fuses information presented by multiple sources of raw data (image, video, sound, text, symbols etc.) at sensor level and is expected to produce more accurate results than the system that integrate information at later stages due to the availability of more information [4-5], . In 2003, Liu and Chen [1], propose a face mosaic king technique. This is a method for combining two or more images of the same face. The authors used a 3D ellipsoidal model to approximate human head images. Later, using geometric mapping, authors projected 2D face images onto the ellipsoidal model and utilized CMU PIE database and a patch based probabilistic model for classification. Another key contribution in this area is the research reported. The authors proposed an approach to combine information obtained from face and palmprint image using particle swarm optimization (PSO) [2-3]. The Kernel Direct Discriminant Analysis (KDDA) and the nearest neighbor method are used for feature extraction and classification. Using FRGC face database and polyU palmprint database, the authors tested the recognition performance with match score level fusion and with genetic algorithm applied on the same set of databases [6], [9].

\footnotetext{
${ }^{1}$ Department of Computer Science \& Engineering Shri Venkateshwara University, Gajraula Amroha, U.P, INDIA

${ }^{2}$ Dept. of Computer Science \& Engineering, HCTM Technical Campus, Kaithal (Haryana)
} 
One of the contributions of rank aggregation research is the work reported in which rankings of documents are combined in order to produce a consensus ranking. Their proposed method was based on decision rules and showed better performance over other positional data fusion methods. Another key contribution to the fuzzy fusion domain of literature is the work of Wang et al. where authors used fuzzy fusion for multimodal medical image application [7]. To overcome the problem of blurriness of the most medical images, the authors proposed a new method of medical image fusion using fuzzy radial basis function neural networks, which is functionally equivalent to T-S fuzzy model. Genetic algorithm was used to train the networks. The research outcome demonstrated good performance when compared to other methods for blurry images. Thus fusion at the rank level is a feasible approach compared to others which consolidates outputs of different classifiers in which no actual matching scores but only the relative positions of the user/identifier are needed.

Fuzzy logic based fusion is another impressive information fusion approach which has been applied in many different applications for the past years. This fusion method uses fuzzy logic and thus can provide the level of confidence of the final output. Researchers investigated different biometric identifiers based on several factors including application scenario, associated cost and availability of the identifiers [8].

\section{PERFORMANCE MEASURES}

There are a number of biometric error types, expressed in error rates or error percentages. Usually the performance of biometric systems is measured in terms of two error rates, False Accept Rate (FAR) and False Reject Rate (FRR). The FAR refers to the errors that the biometric system makes by incorrectly declaring a match between two different individuals and it is called a Type II error. The FRR refers to the errors that the biometric system makes when by mistake it does declare a match between biometric samples from the same individual and is called a Type I error. Some groups also call FAR as False Non-Match Rate (FNMR) and FRR as False Match Rate (FMR). To evaluate the performance of a biometric system usually a graph of FAR vs. FRR is plotted, recognized as a Receiver Operating Characteristic (ROC) curve. ROC curve presents a nondimensional, basic technical performance measure for comparing two or more biometric systems.

Figure 1 indicates that for different biometric applications different operating points should be chosen which would result in different FRR and FAR. Sometimes the ROC curve is plotted as GAR (Genuine Accept Rate) vs. FAR. The complement of FRR is GAR (GAR = $1-$ FRR). The ROC curve is a precise and complete specification of the performance of a biometric system, and it is very beneficial in comparing the performance of two or more biometric systems. It also displays the trade-offs between FAR and FRR over a wide range of thresholds.

Besides the above-mentioned errors, Equal Error Rate (EER) and d-prime are also used to summarize the accuracy of a biometric system. EER is the point on the ROC curve where the FAR equals the FRR or it is the error rate occurring when the decision threshold of a system is set so that the proportion of false rejections are approximately equal to the proportion of false acceptances.

For example in Figure 1, the EER is around 18\%. The EER can inform us if one system performs better than other but only in narrow range of points $\mathrm{FAR}=(\mathrm{EEa}, \mathrm{EEb})$ and $\mathrm{FRR}=(\mathrm{EEa}, \mathrm{EEb})$. Beyond that range, the ROC curves may cross over each other and the EER would be invalid. That is why the EER is an unreliable summary of system accuracy.

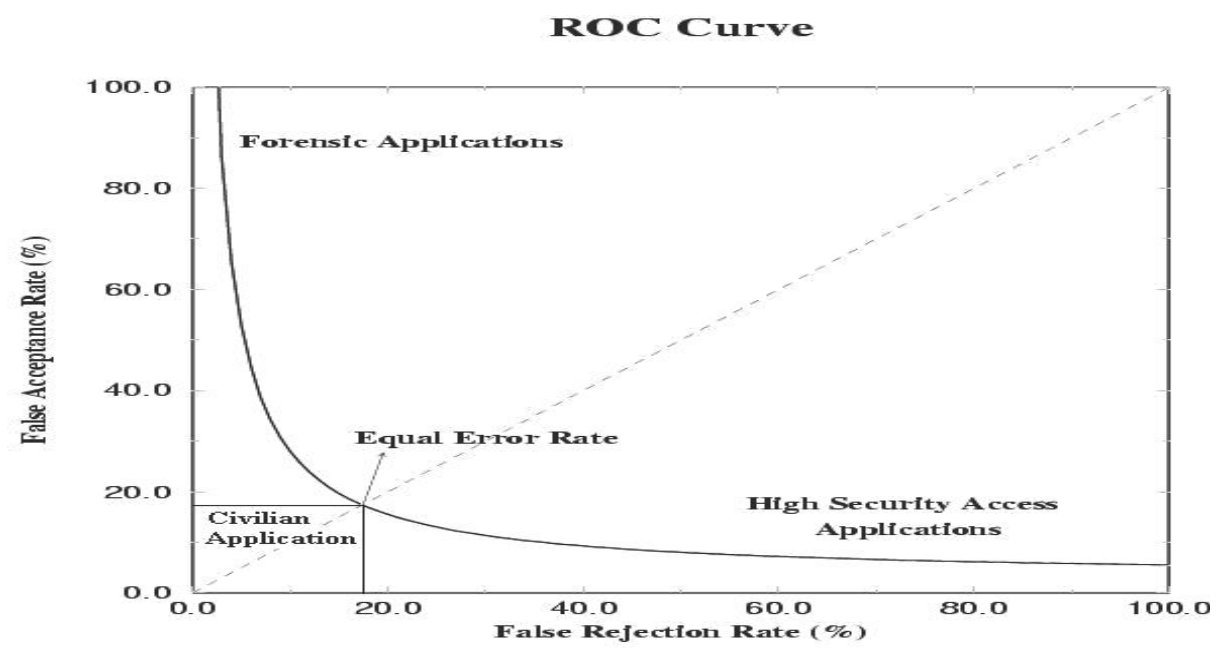

Figure 1: FAR vs. FRR ROC Curve 
There are two more types of errors, namely Failure to Enroll (FTE) and Failure to Acquire (FTA) rates. The FTE rate measures the percentage of individuals who cannot be enrolled in the system. The FTA rate measures the percentage of time in which the biometric system cannot obtain the raw biometric data during enrollment or authentication. It is obvious that every biometric system makes mistakes, and the true value of these errors cannot be computed or theoretically established. It is only possible to calculate statistical estimates of the errors once we have the database of biometric samples.

\section{COMPARATIVE ANALYSIS OF MULTIMODAL BIOMETRIC FUSION APPROACHES}

Table 1: Comparative Analysis of Multibiometric Systems Fusion Approaches

\begin{tabular}{|c|c|c|c|}
\hline $\begin{array}{l}\text { Type of Biometric } \\
\text { Information Fused }\end{array}$ & $\begin{array}{l}\text { Level of } \\
\text { Fusion }\end{array}$ & $\begin{array}{c}\text { Fusion } \\
\text { Methodology }\end{array}$ & Performance \\
\hline $\begin{array}{l}\text { 2D camera, range } \\
\text { scanner and IR camera } \\
\text { for face }\end{array}$ & $\begin{array}{l}\text { Match } \\
\text { score }\end{array}$ & $\begin{array}{l}\text { Weighted sum } \\
\text { rule }\end{array}$ & $\begin{array}{l}\text { It examines individual and multimodal face } \\
\text { recognition using } 2 \mathrm{D}, 3 \mathrm{D} \text { and infrared images } \\
\text { of the same set of subjects. For individual trait, } \\
\text { recognition rate of } 90.6 \% \text { for } 2 \mathrm{D}, 91.9 \% \text { for } \\
3 \mathrm{D} \text { and } 71.0 \% \text { for } \mathrm{IR} \text { is obtained. Combining } \\
\text { each pair of traits, recognition rate of } 98.7 \% \\
\text { for } 2 \mathrm{D}-3 \mathrm{D}, 96.6 \% \text { for } 2 \mathrm{D} \text {-IR and } 98.0 \% \text { for } \\
3 \mathrm{D}-\mathrm{IR} \text { is found. When all three traits are } \\
\text { combined, } 100 \% \text { recognition is obtained. }\end{array}$ \\
\hline $\begin{array}{l}\text { Red, Green, } \\
\text { channels for face }\end{array}$ & $\begin{array}{l}\text { Feature; } \\
\text { match } \\
\text { score }\end{array}$ & $\begin{array}{l}\text { Feature selection } \\
\text { and } \\
\text { concatenation; } \\
\text { sum rule }\end{array}$ & $\begin{array}{l}\text { It discusses fusion at the feature level in } 3 \\
\text { different scenarios: (i) fusion of PCA and } \\
\text { LDA coefficients of face; (ii) fusion of LDA } \\
\text { coefficients corresponding to the R, G, B } \\
\text { channels of a face image; (iii) fusion of face } \\
\text { and hand traits. For first scenario, } \\
\text { performance of LDA-based matcher is found } \\
\text { much higher than PCA-based matcher, e.g. at } \\
\text { a FAR = 0:01\%, GAR using PCA technique is } \\
\sim 50 \% \text { and LDA technique is } \sim 80 \% \text {. For } \\
\text { second and third scenario, ROC curve is } \\
\text { plotted to show the performance gain. }\end{array}$ \\
\hline $\begin{array}{l}\text { Face, fingerprint and } \\
\text { hand geometry }\end{array}$ & $\begin{array}{l}\text { Match } \\
\text { score }\end{array}$ & $\begin{array}{ll}\text { Sum rule; } & \text { trees; } \\
\text { decision } & \text { treear } \\
\text { linear } & \\
\text { discriminant } & \\
\text { function } & \end{array}$ & $\begin{array}{l}\text { The experiments show that the sum rule } \\
\text { performs better than the decision tree and } \\
\text { linear discriminant classifiers. The sum rule } \\
\text { has a corresponding FAR of } 0.03 \% \text { and a FRR } \\
\text { of } 1.78 \% \text { suggesting better performance than } \\
\text { the other two classifiers. }\end{array}$ \\
\hline $\begin{array}{lll}\text { Face } & \text { (PCA, LDA, } \\
\text { ICA })\end{array}$ & $\begin{array}{l}\text { Match } \\
\text { score }\end{array}$ & $\begin{array}{l}\text { Sum rule; RBF } \\
\text { network }\end{array}$ & $\begin{array}{l}\text { It integrates the output matching scores of } \\
\text { three face recognition approaches- PCA, } \\
\text { ICA, LDA. Experiments are conducted on a } \\
\text { face database containing } 206 \text { subjects and } \\
\text { found that the proposed combination } \\
\text { approaches outperform individual classifiers. }\end{array}$ \\
\hline $\begin{array}{l}\text { Optical and capacitive } \\
\text { fingerprint sensors }\end{array}$ & $\begin{array}{l}\text { Match } \\
\text { score }\end{array}$ & $\begin{array}{ll}\text { Sum and } & \text { product } \\
\text { rules; } & \text { logistic } \\
\text { regression } & \end{array}$ & $\begin{array}{l}\text { It is shown by experiments that a significant } \\
\text { performance improvement can be obtained by } \\
\text { decision-level fusion of two fingerprint } \\
\text { capture devices. Performances are assessed } \\
\text { and compared in terms of: Equal Error Rate } \\
\text { (EER), Generalization errors, i.e., FAR and } \\
\text { FRR, Total Error Rate (TER). }\end{array}$ \\
\hline
\end{tabular}




\begin{tabular}{|c|c|c|c|}
\hline $\begin{array}{l}\text { Hand (geometry and } \\
\text { texture features) }\end{array}$ & $\begin{array}{l}\text { Feature; } \\
\text { match score }\end{array}$ & $\begin{array}{l}\text { Feature } \\
\text { concatenation; } \\
\text { max rule }\end{array}$ & $\begin{array}{l}\text { Single sensor is used to acquire both images. } \\
\text { The ROC curves for three distinct cases are } \\
\text { plotted; (i) hand geometry alone, (ii) palmprint } \\
\text { alone, and (ii) using match score level fusion } \\
\text { with max rule. Results show that the match } \\
\text { score level fusion scheme, with max rule, } \\
\text { achieves better performance than those for } \\
\text { fusion at the feature level. }\end{array}$ \\
\hline Face and fingerprint & $\begin{array}{l}\text { Match } \\
\text { score }\end{array}$ & Product rule & $\begin{array}{l}\text { It overcomes the limitations of both face } \\
\text { recognition systems and fingerprint } \\
\text { verification systems. Experimental results } \\
\text { demonstrate that the system performs well } \\
\text { than individual traits. }\end{array}$ \\
\hline Face and iris & $\begin{array}{l}\text { Match } \\
\text { score }\end{array}$ & $\begin{array}{l}\text { Sum rule; } \\
\text { weighted } \quad \text { sum } \\
\text { rule; Fisher's } \\
\text { linear } \\
\text { discriminant; } \\
\text { neural network }\end{array}$ & $\begin{array}{l}\text { The total error rate (i.e., FAR+FRR) is } \\
\text { calculated at various thresholds. Fusion based } \\
\text { on the RBF neural network produced the } \\
\text { highest verification accuracy. Weighted sum } \\
\text { rule is the best approach when compared with } \\
\text { the sum rule and the Fisher rule. }\end{array}$ \\
\hline Face and voice & $\begin{array}{l}\text { Match } \\
\text { score }\end{array}$ & $\begin{array}{l}\text { SVM; multilayer } \\
\text { perceptron; } \\
\text { decision tree; } \\
\text { Fisher's linear } \\
\text { discriminant; } \\
\text { Bayesian } \\
\text { classifier }\end{array}$ & $\begin{array}{l}\text { The experimental results show that support } \\
\text { vector machines and Bayesian classifier } \\
\text { achieve almost the same performances, and } \\
\text { both outperform the other evaluated } \\
\text { classifiers. }\end{array}$ \\
\hline $\begin{array}{l}\text { Palmprint (Gabor, } \\
\text { line, appearance- } \\
\text { based features) }\end{array}$ & $\begin{array}{l}\text { Match } \\
\text { score; } \\
\text { decision }\end{array}$ & $\begin{array}{l}\text { Sum rule (for } \\
\text { Gabor and line } \\
\text { features) followed } \\
\text { by product rule; } \\
\text { SUM; MAX; } \\
\text { MIN; AND rule }\end{array}$ & $\begin{array}{l}\text { Combination of palmprint representations } \\
\text { achieves better performance than individual } \\
\text { palmprint representation. The comparative } \\
\text { performance evaluation show that the best } \\
\text { performance is achieved from the Gabor filter } \\
\text { based representation as compared to the Line- } \\
\text { or PCA based representations. POS rule } \\
\text { achieved best performance as compared to } \\
\text { SUM, AND, MAX, PROD, or MIN rule. }\end{array}$ \\
\hline
\end{tabular}

\section{CONCLUSION}

In the comparative chart shown in Table 1, the authors of this thesis have compared some of the representative work in the multibiometric literature based on the above three parameters. It is clear from the table that fusion of multiple biometric traits i.e. multimodal biometric system and information fusion at the match score level are the most commonly used approaches in multibiometric systems. Fusion at sensor level suffer from sensor interoperability problem, fusion at feature level suffer from feature set incompatibility problem, and fusion at decision level contains least amount of information i.e. the decisions output by the individual biometric matchers to be fused. Among the type of biometric information fused i.e. multi-sensor, multi-algorithm, multiinstance, multi-sample, and multimodal, the fifth multibiometric system i.e. multimodal seems better choice because it is more robust to noise, addresses the problem of non-universality, involves more than one biometric trait, improves the matching accuracy, and provides protection against spoof attacks. Fusion methodologies depend upon the type of biometric information fused and level of fusion.

\section{REFERENCES}

[1] X. Liu and T. Chen, "Geometry-assisted statistical modeling for face mosaicing", Proceeding of IEEE ICIP, 2: 883 - 886, September 2003.

[2] Y. S. Sangwan, S. Jangra and K. Kuhar, "Facial Skin Segmentation using BFO and PSO”, Int'1 J. of Control Theory and Applications, Vol. 10 (2017), Issue No. 18, Pg. 31-39, ISSN: 0974-5572. 
[3] T. Kumar, S. Jangra and S. Bhushan, "Face Recognition with Decision Tree using SVM and SURF", Published in, "Int'1 J. of Control Theory and Applications", Vol. 10 (2017), Issue No. 15, Pg. 173-180, ISSN: 0974-5572.

[4] S. Jangra, S. Goel and A. Selwal, "Hyper Spectral Image Restoration Approach using LRMR and LDA”, IEEE Xplorer, Pg. 415-418, 2015, e-ISBN: 978-1-5090-0148-4.

[5] Selwal, S.K Gupta and S. Jangra, "A Hybrid Template Security Scheme for Multimodal Biometric System based on Fingerprint and Hand Geometry", Int'1 J. of Control Theory and Applications, Vol. 10 (2017), Issue No. 15, Pg. 143-152, ISSN: 0974-5572.

[6] X. Y. Jing and D. Zhang, "A face and palmprint recognition approach based on discriminant DCT feature extraction", IEEE Trans. on Syst. Man Cybern B, vol. 34, no. 6, pp. 2405-2415, 2004.

[7] Y. Wang, T. Tan and A. K. Jain,"Combining face and iris biometrics for identity verification," Lecture Notes in Computer Science, vol. 2688, pp. 805-813, 2003.

[8] J. Yang, A.F. Frangi, J.Y. Yang, D. Zhang, Z. Jin,"KPCA plus LDA: A complete kernel fisher discriminant framework for feature extraction and recognition," IEEE Transactions on Pattern Analysis and Machine Intelligence, vol. 27, pp. 230-244, 2005.

[9] Ziad M. Hafed, "Face Recognition Using DCT", International Journal of Computer Vision, 2001, pp. 167-188.

[10] A. Selwal, S.K Gupta and S. Jangra, "A Hybrid Template Security Scheme for Multimodal Biometric System based on Fingerprint and Hand Geometry", Int'l J. of Control Theory and Applications, Vol. 10 (2017), Issue No. 15, Pg. 143-152, ISSN: 0974-5572.

[11] Shant Kaushik and Surender Jangra, "Finger Vein Biometric Authentication Scheme using Repeated Line Tracking and DWPT based Scheme", Int'1 J. of Control Theory and Applications, Vol. 10 (2017), Issue No. 18, Pg. 289-294, ISSN: 0974-5572.

[12] A. Selwal, S.K Gupta and Surender, "Low Overhead Octet Indexed Template Security Scheme for Multimodal Biometrics System”, Journal of Intelligent \& Fuzzy System 32 (2017), pp. 3325-3337, DOI:10.3233/JIFS-169274, IOS Press.

[13] A. Selwal, S.K. Gupta and S. Kumar, "A Scheme for Template Security at Feature Fusion Level in Multimodal Biometric System", Advances in Science and Technology Research Journal, Vol. 10, No. 31, Sept. 2016, Pg. 23-30.

[14] A. Selwal, S.K. Gupta and Surender, "Fuzzy Analytic Hierarchy Process based Template Data Analysis of Multimodal Biometric Conceptual", Procedia Computer Science (Elsevier), 85 (2016), Pg. 899-905.

[15] A. Selwal, S.K. Gupta and Surender, "Template Security Analysis of Multimodal Biometric Frameworks based on Fingerprint and Hand Geometry", Perspectives in Science (Elsevier), (2016) 8, Pg.705-708, ISSN: 2212-0209.

[16] A. Selwal, S. K. Gupta, Surender and Anubhuti, "Performance analysis of template data security and protection in Biometric Systems, IEEE Xplore, 2015, pp. 1-6. e-ISBN : 978-1-4673-8253-3. 